\title{
Determination of trace elements in human milk by inductively coupled plasma sector field mass spectrometry (ICP-SFMS)
}

\author{
Thomas Prohaska, ${ }^{a}$ Gunda Köllensperger, ${ }^{a}$ Michael Krachler, ${ }^{b}$ Kristof De Winne, ${ }^{c}$ \\ Gerhard Stingeder $^{a}$ and Luc Moens ${ }^{c}$ \\ ${ }^{a}$ Institute of Chemistry, University of Agricultural Sciences, BOKU Vienna, Muthgasse 18, A- \\ 1190 Vienna, Austria. E-mail: prohaska@mail.boku.ac.at \\ ${ }^{b}$ Institute of Applied Physical Chemistry, Research Centre Jülich, D-52425 Jülich, Germany \\ ${ }^{c}$ Laboratory of Analytical Chemistry, University of Gent, Proeftuinstraat 86, B-9000 Gent, \\ Belgium
}

Received 31st August 1999, Accepted 7th December 1999

Published on the Web 6th March 2000

The potential of high resolution inductively coupled plasma sector field mass spectrometry (ICP-SFMS) was evaluated to quantify reliably various toxic and essential elements (Al, Sc, Ti, V, Cr, Mn, Fe, Ni, Co, Cu, As, $\mathrm{Ag}, \mathrm{Pt}, \mathrm{Au}, \mathrm{Pb}$ ) in human milk and infant formulae with respect to sensitivity, spectral and non-spectral interferences, blank levels, relative stability and accuracy. Some elements of potential interest such as Ti, V, Cr, $\mathrm{Mn}, \mathrm{Fe}, \mathrm{Ni}, \mathrm{Co}$ and As are significantly interfered by polyatomic ions and cannot be determined under routine conditions without using high mass resolution, since interference levels vary significantly with the composition of the milk matrix. A microconcentric nebuliser in combination with a membrane desolvation unit was tested with respect to signal enhancement and reduction of interferences. In general, an increase of the signal intensities up to a factor of 5 was observed, whereas not all spectral interferences can be reduced to a negligible amount (only oxide containing ions to some extent). Moreover the use of the $\mathrm{N}_{2}$ as the make-up gas did not improve the sensitivity but led to additional $\mathrm{N}$-containing polyatomic interferences (e.g., for $\mathrm{V}, \mathrm{Cr}$ and $\mathrm{Mn}$ ). The use of a torch shielded by a Pt electrode did lead to the same signal intensities both for the conventional MCN100 and the MCN6000 with membrane desolvation. The investigation of In, Re, Ru, and Rh as internal standard showed that not all elements can be corrected for matrix suppression without using an additional correction factor derived from an approximate matrix composition. A series of milk samples was investigated using the optimised analytical set-up and compared to infant milk formulae. Trace element levels in instant milk formulae are significantly influenced by the quality of tap water used for preparation.

\section{Introduction}

Optimal growth and development of infants can be guaranteed only when the intake of food and water provides the required doses of all essential (bulk and trace) elements and delivers only ineffectual doses of toxic elements. Breast milk is normally the only source of food in the early stages of life and consequently must meet the dietary requirements of the infants. Sufficient evidence for detrimental consequences of sub-optimal intake of essential trace elements (growth retardation, anaemia, disturbed immune balance, impaired organ functions) is available. ${ }^{1-4}$ Uptake of essential trace elements in excess may, on the other hand, have toxic effects. ${ }^{5}$ However, the optimal daily doses of trace elements are still under debate ${ }^{6,7}$ and recent investigations have shown that the concentration of trace elements changes significantly during lactation ${ }^{8}$ and have monitored trace element transfer from the mother to the new-born. ${ }^{9}$ When term infants are not breastfed or breast feeding is discontinued early, appropriate milk formulae replace human milk. Many of the essential trace elements are re-sorbed in the intestinal tract to a smaller extent from formulae milk than from human milk. ${ }^{10}$ Consequently, milk powders are often fortified to compensate for low bioavailability. Usually, this is accomplished irrespective of the natural concentrations of trace elements in the powders.

Though concentrations of trace elements in human milk have been determined repeatedly, most studies focused on single elements and did not consider the whole lactation period. ${ }^{11-19}$ Also reports on trace element concentrations in formulae are only limited. Extremely low concentrations (low $\mathrm{ng} \mathrm{g}^{-1}$ to $\mathrm{pg} \mathrm{g}^{-1}$ range) of various trace elements still pose a challenge in terms of accurate and precise multi-element determination by most of the analytical techniques. Nowadays, ICP-MS has become the standard analytical technique for ultratrace elemental analysis offering multi-element capability, excellent sensitivity and accuracy. ${ }^{20,21}$ However, the technique is well known to suffer from unwanted spectral and non spectral interferences, ${ }^{21-23}$ which cannot be resolved by low resolution quadrupole ICP-MS and which lead to a significant background equivalent concentration for many important elements such as $\mathrm{Fe}, \mathrm{Co}, \mathrm{As}, \mathrm{Cr}$, Se and V. This is crucial, if spectral interferences change with the elemental composition of the analysed samples. The use of high resolution sector field mass spectrometry (HR-ICP-SFMS) allows the optimal resolution for each element under investigation to be selected and the peak of interest from the adjacent interference to be separated. ${ }^{24}$ Moreover, ICP-SFMS offers higher sensitivity owing to improved and not mass dependent ion transmission under low resolution operating settings compared to ICP-QMS. 22

The following study focused mainly on the analysis of trace elements hampered from interferences using low mass resolution (Al, Sc, Ti, V, Cr, Mn, Fe, Ni, Co, Cu, As). These elements have not been analysed in detail in human milk so far. Additionally selected trace elements $(\mathrm{Ag}, \mathrm{Pt}, \mathrm{Au}, \mathrm{Pb})$ were 
determined using low mass resolution exploiting the enhanced sensitivity of sector field mass spectrometers.

\section{Experimental}

\section{Analytical set-up}

Measurements were carried out by means of a Finnigan MAT ELEMENT (Finnigan MAT, Bremen, Germany) high resolution ICP-SFMS. This instrument is equipped with a double focusing mass separator consisting of a magnetic and an electric sector field of reversed Nier-Johnson geometry and has predefined resolution settings ( $\mathrm{m} / \Delta m$ at $10 \%$ valley definition) of 400 (low), 4000 (medium) and 8000 (high). Instrumental operating conditions are outlined in Table 1 . The instrument was equipped with a microconcentric nebuliser (MCN100, Cetac Technologies, Omaha, Nebraska USA) a water-cooled $\left(4{ }^{\circ} \mathrm{C}\right)$ double pass Scott-type spray chamber and a torch equipped with a Pt-guard electrode (CD1, Finnigan MAT, Bremen, Germany). Additionally, a microconcentric nebuliser in combination with a membrane desolvation system (MCN6000, Cetac Technologies) was used as an alternative introduction system.

Sample transport to the nebuliser was established by using a peristaltic pump (Perimax, Spetec, Vienna, Austria) and switching between rinse and sample solution was established by a manually switched valve in order to prevent clogging of the nebuliser by air bubbles, which cause backpressure of the sample gas at the nebuliser tip (discussed later). All measurements were performed in a class 10.000 clean room laboratory.

\section{Reagents and standards}

All preparations of samples and standards were carried out in class 100 clean benches. Analytical reagent grade nitric acid (Janssen Chimica, Geel, Belgium) was additionally cleaned by double sub-boiling distillation in an ultrapure quartz apparatus (Milestone-MLS GmbH, Leutkirch, Germany). Purified water obtained using a reagent I grade water $\left(>10 \mathrm{Mohm} \mathrm{cm}^{-1}\right.$ resisitvity according to ISO 3696 water specifications) purification system (HQ, USF, Vienna, Austria) was further purified in a quartz sub-boiling system (Milestone-MLS GmbH, Leutkirch, Germany). Aqueous (nitric acid in water 1+99) calibration standards were prepared by diluting $1.000 \mu \mathrm{g} \mathrm{g}^{-1}$ single element ICP-MS standard solutions (Merck, Darmstadt, Germany). Quantification of the elemental concentration was performed using external calibration with aqueous standard solutions and internal standardisation using ${ }^{103} \mathrm{Rh},{ }^{115} \mathrm{In}$ and ${ }^{187} \operatorname{Re}$ (all at $1 \mathrm{ng} \mathrm{g}^{-1}$ in the final solution) as internal standards. Calibration standards were selected for each element according to the expected concentration range as derived from semiquantitative measurements prior to the final quantification.

Table 1 Instrumental setup and instrument operation parameter settings

\begin{tabular}{ll}
\hline Torch & Sapphire injector, CD-1 torch \\
Nebulizer & MCN100, MCN6000 \\
Spray chamber & Scott-type, cooled to $4{ }^{\circ} \mathrm{C}$ \\
Cones & Ni sampler $(1.1 \mathrm{~mm}$ orifice id) \\
& Ni skimmer $(0.8 \mathrm{~mm}$ orifice id) \\
Sample uptake & Perimax peristaltic pump \\
Rf power & $1250 \mathrm{~W}$ \\
Plasma gas flow & $12 \mathrm{~L} \mathrm{~min}$ \\
Auxiliary gas flow & $0.9 \mathrm{~L} \mathrm{~min}$ \\
Sample gas flow & $1.0 \mathrm{~L} \mathrm{~min}$ \\
Samples per peak & 50 \\
Dwell time & $0.001 \mathrm{~s}$ \\
Mass window & $150 \%$ \\
Search window & $50 \%$ \\
Integration window & $60 \%$ \\
Number of scans & 25 \\
\hline
\end{tabular}

A certified reference water solution (TM27, Canadian National Research Lab., Vancouver, Canada) was used for control of the aqueous calibration and a certified milk reference standard (BCR-063 (natural level), IRMM, Geel, Belgium) was used for quality control of the final quantification of elemental concentrations in the milk samples.

\section{Human milk and infant formulae}

Human milk samples were collected from healthy mothers, who had successfully given birth to mature babies after uneventful pregnancies at the University Maternity Clinic in Graz, Austria during 1995 and 1996. These milk samples were obtained from mothers, who had visited the clinic to donate milk to the human milk bank, or to have their babies examined by a paediatrician. They had all given their consent after they had been informed about the purpose of the investigation. Before the mothers started breast feeding (second breast feeding of a day, approximately $10 \mathrm{am}$ ), a milk sample was collected with an electric breast pump (Sanesco, Vienna, Austria). The breast was cleaned with doubly distilled water and was air dried prior to collection of the milk. All parts of the breast pump that were in contact with the milk samples were cleaned with doubly distilled water at $75^{\circ} \mathrm{C}$ for at least $5 \mathrm{~min}$ The samples were transferred into polyethylene tubes that had been randomly checked for possible contamination, and kept at $-20^{\circ} \mathrm{C}$ prior to mineralization.

Additionally, four treated milk powders bought in a local super market were investigated. The powders were two preformulae (BEBA1 Dauer-Milchnahrung (Nestlé) and Ja Natürlich Pre-Säuglings Milchnahrung (Ja Natürlich)) and two follow-up formulae (BEBA2 Folge-Milchnahrung (Nestlé) and Ja Natürlich Säuglings Folgemilch 2 (Ja Natürlich)). All four powder samples are declared to be enriched with $\mathrm{Fe}$ and $\mathrm{Cu}$.

\section{Sample preparation}

A closed, pressurised, high-performance microwave digestion unit (MLS 1200 MEGA, MLS GmbH, Leutkirch, Germany) equipped with a rotor for ten Teflon vessels designed for pressures up to 30 bar was used for mineralisation. Aliquots of human milk $(\approx 1.5 \mathrm{ml})$ or of milk powder $(\approx 300 \mathrm{mg})$ weighed to $0.1 \mathrm{mg}$ were placed into the digestion vessels and mixed with $1.5 \mathrm{ml}$ concentrated $\mathrm{HNO}_{3}$ and $0.5 \mathrm{ml}$ high purity hydrogen peroxide (Suprapur 30\%, Merck, Darmstadt, Germany) and mineralised by the optimised procedure reported previously. ${ }^{8}$ The samples were finally diluted to $20 \mathrm{~mL}$ using purified water prior to ICP-MS analysis.

\section{Results and discussion}

\section{Spectral interferences and comparison of the nebulising systems}

In a detailed study of spectral interferences in the milk matrix, spectra were recorded in the vicinity of each metal peak of interest (the mass range corresponding to $\pm 0.05 \mathrm{u}$ from the centre) using both high and medium resolution mode $(m / \Delta m=8000$ and 4000 , respectively) and the MCN100 as the introduction system. Additionally, a grounded platinum electrode is inserted between quartz ICP torch and the RF coil (CD1 option) to prevent capacitive coupling from the load coil into the ICP. The ICP is then sustained by pure inductive coupling and the secondary discharge between the ICP and mass spectrometer sampling cone is eliminated. The use of the guard electrode results in a signal enhancement of a factor of 10 compared to the conventional torch. Spectra were monitored in an aqueous multi-element reference standard, in sub-boiled water, in the digested and diluted milk solution and in the corresponding blank. In this way the background equivalent concentration of the interferences could be assessed. Most 
Table 2 Spectral interferences in digested milk matrix; interferences which vary with the composition of the milk matrix are in bold

\begin{tabular}{|c|c|}
\hline Isotope & Interferences \\
\hline${ }^{27} \mathrm{Al}$ & ${ }^{12} \mathrm{C}^{14} \mathrm{~N}^{1} \mathrm{H},{ }^{11} \mathrm{~B}^{16} \mathrm{O}$ \\
\hline${ }^{45} \mathrm{Sc}$ & ${ }^{28} \mathrm{SiO}^{1} \mathrm{H},{ }^{12} \mathbf{C}^{\mathbf{1 6}} \mathbf{O}_{\mathbf{2}}{ }^{\mathbf{1}} \mathbf{H},{ }^{11} \mathbf{B}^{\mathbf{1 6}} \mathbf{O}_{\mathbf{2}} \mathbf{H}_{\mathbf{2}},{ }^{29} \mathrm{Si}^{16} \mathrm{O}$ \\
\hline${ }^{47} \mathrm{Ti}$ & ${ }^{31} \mathrm{P}^{16} \mathrm{O},{ }^{40} \mathrm{Ar}^{7} \mathrm{Li},{ }^{15} \mathrm{~N}^{16} \mathrm{O}_{2}$ \\
\hline${ }^{48} \mathrm{Ti}$ & ${ }^{32} \mathrm{~S}^{16} \mathrm{O},{ }^{31} \mathrm{P}^{16} \mathrm{O}^{1} \mathrm{H},{ }^{48} \mathrm{Ca}$ \\
\hline${ }^{51} \mathrm{~V}$ & ${ }^{35} \mathrm{Cl}^{16} \mathrm{O},{ }^{37} \mathrm{Cl}^{14} \mathrm{~N}$ \\
\hline${ }^{52} \mathrm{Cr}$ & ${ }^{40} \mathrm{Ar}^{12} \mathrm{C},{ }^{36} \mathrm{Ar}^{16} \mathrm{O},{ }^{38} \mathrm{Ar}^{14} \mathrm{~N},{ }^{35} \mathrm{Cl}^{16} \mathrm{O}^{1} \mathbf{H}$ \\
\hline${ }^{53} \mathrm{Cr}$ & ${ }^{37} \mathrm{Cl}^{16} \mathrm{O},{ }^{40} \mathrm{Ar}^{13} \mathrm{C}$ \\
\hline${ }^{55} \mathrm{Mn}$ & ${ }^{40} \mathrm{Ar}{ }^{15} \mathbf{N},{ }^{40} \mathrm{Ar}^{14} \mathbf{N}^{1} \mathrm{H},{ }^{39} \mathrm{~K}^{16} \mathrm{O}$ \\
\hline${ }^{56} \mathrm{Fe}$ & ${ }^{40} \mathrm{Ar}^{16} \mathrm{O},{ }^{40} \mathrm{Ca}^{16} \mathrm{O}$ \\
\hline${ }^{57} \mathrm{Fe}$ & ${ }^{40} \mathrm{Ar}^{16} \mathrm{O}^{1} \mathrm{H},{ }^{41} \mathbf{K}^{16} \mathbf{O}$ \\
\hline${ }^{58} \mathrm{Ni}$ & ${ }^{40} \mathrm{Ar}^{18} \mathrm{O},{ }^{58} \mathrm{Fe},{ }^{23} \mathrm{Na}^{35} \mathrm{Cl}$ \\
\hline${ }^{60} \mathrm{Ni}$ & ${ }^{44} \mathrm{Ca}^{16} \mathrm{O},{ }^{23} \mathrm{Na}^{37} \mathrm{Cl},{ }^{36} \mathrm{Ar}^{24} \mathrm{Mg}$ \\
\hline${ }^{59} \mathrm{Co}$ & ${ }^{40} \mathrm{Ar}^{18} \mathrm{O}^{1} \mathrm{H},{ }^{40} \mathrm{Ar}^{19} \mathrm{~F},{ }^{42} \mathrm{Ca}^{16} \mathrm{O}^{1} \mathrm{H},{ }^{42} \mathrm{Ca}^{17} \mathrm{O},{ }^{43} \mathrm{Ca}^{16} \mathrm{O}$ \\
\hline${ }^{63} \mathrm{Cu}$ & ${ }^{40} \mathrm{Ar}^{23} \mathrm{Na},{ }^{31} \mathrm{P}^{16} \mathrm{O}_{2}$ \\
\hline${ }^{75}$ As & ${ }^{40} \mathrm{Ar}{ }^{35} \mathrm{Cl}$ \\
\hline
\end{tabular}

spectral interferences could be separated using the medium mass resolution settings, except $\mathrm{Ar}-\mathrm{Cl}$ interferences on ${ }^{75} \mathrm{As}$, which requires high resolution settings. Moreover, these experiments identified interferences deriving from the milk matrix, which cannot be corrected for by blank correction solely. Table 2 gives an overview of the main spectral interferences observed in the milk matrix. Interferences, which depend on the composition of the milk, are given in bold. It can be seen that, for the elements $\mathrm{Al}, \mathrm{Sc}, \mathrm{Ti}, \mathrm{V}, \mathrm{Cr}, \mathrm{Fe}$, $\mathrm{Ni}, \mathrm{Co}, \mathrm{Cu}$ and $\mathrm{As}$, measurements in medium or high (for As) resolution settings are a prerequisite, since the major interfering molecular ions change due to the composition of the milk matrix. In the case of e.g., $\mathrm{Ti}$, the isotope ${ }^{47} \mathrm{Ti}$ is significantly interfered by ${ }^{31} \mathrm{P}^{16} \mathrm{O}$ and ${ }^{15} \mathrm{~N}^{16} \mathrm{O}^{16} \mathrm{O}$ as main interferences whereas the isotope ${ }^{48} \mathrm{Ti}$ is significantly overlapped by the isobaric interference of ${ }^{48} \mathrm{Ca}$ (abundance $0.19 \%$ ). The signal intensity of ${ }^{48} \mathrm{Ca}$ is about two orders of magnitude higher than the ${ }^{48} \mathrm{Ti}$ signal. Fig. 1 shows, as another example, a spectrum of ${ }^{51} \mathrm{~V}$ in the milk matrix, measured at medium mass resolution. The intensity of the spectral interfering peak exceeds the intensity of the $\mathrm{V}$ peak by two orders of magnitude (concentration of $\mathrm{V}$ in solution is about $1 \mathrm{pg} \mathrm{g}^{-1}$ ) making reliable measurement of this element in the low resolution mode almost impossible.

Additionally, the MCN6000 was evaluated as the introduction system to investigate the influence on the signal intensities and the effect of membrane desolvation on the formation of interfering molecular ions. In general, the use of the MCN6000 leads to an increase of the signal intensities of a factor of $5 .^{25}$ The additional use of a Pt shield electrode only leads to an additional increase of a factor of 2 and therefore to a signal enhancement of 10 compared to conventional settings. Thus, both set-ups (MCN100 plus guard electrode and MCN6000 plus guard electrode) show the same signal intensities for the

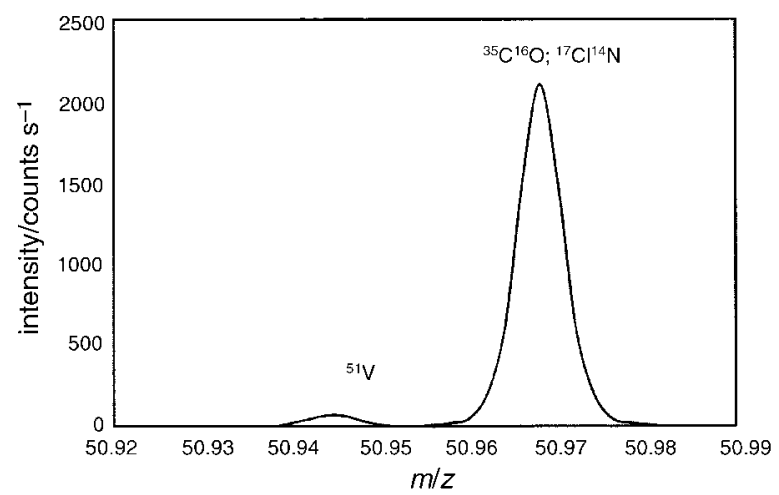

Fig. 1 Mass spectrum of ${ }^{51} \mathrm{~V}$ at medium mass resolution $(\mathrm{m} / \Delta m=4000)$ in a digested milk sample measured using a MCN100. elements of interest. Therefore, the only interest in using this kind of introduction system is the reduction of polyatomic interferences, which is studied in more detail. In general, interferences caused by oxygen $(\mathrm{ArO}, \mathrm{CaO})$ and to a smaller degree carbon (e.g., ArC) are reduced significantly but not always to a negligible amount by means of desolvation. ${ }^{26}$ This can be shown by the ${ }^{40} \mathrm{Ar}^{12} \mathrm{C}$ and ${ }^{36} \mathrm{Ar}^{16} \mathrm{O}$ interferences on ${ }^{52} \mathrm{Cr}$. The interference is one order of magnitude higher than the peak of interest when using the MCN100 but is still $50 \%$ of the ${ }^{52} \mathrm{Cr}$ signal after desolvation. Fig. 2 shows medium resolution spectra for ${ }^{47} \mathrm{Ti}$ obtained with a MCN100 and the MCN6000. It is obvious, that the Ti signal remains unaffected, whereas the ${ }^{31} \mathrm{P}^{16} \mathrm{O}$ signal is reduced significantly, even if not eliminated, to a negligible amount. The same is true for other oxide-containing polyatomic interferences (e.g., on $\mathrm{Sc}, \mathrm{V}, \mathrm{Fe}$ ), whereas, for ${ }^{60} \mathrm{Ni}$ and ${ }^{59} \mathrm{Co}$, oxygen-containing polyatomic species could be reduced to a negligible amount. Therefore, it is evident, that most isotopes of interest should be measured using medium resolution settings of the ICP-SFMS.

In addition, the use of $\mathrm{N}_{2}$ as makeup gas for the MCN6000 was investigated, since it can be directly introduced into the nebuliser and is subject to increased signal intensities due to altered plasma conditions. ${ }^{11}$ The system was optimised by changing both the sweep gas (Ar) flow and make-up gas $\left(\mathrm{N}_{2}\right)$ flow of the MCN6000 iteratively. It was found that the addition of $\mathrm{N}_{2}$ improved the signal intensities up to $20 \%$. To evaluate the origin of the increase of the signal intensity, $\mathrm{N}_{2}$ was changed to $\mathrm{Ar}$ and the flow rates were kept at the same settings. Since the same effect on the intensities could be observed, it can be deduced that the introduction of an additional gas changes the intensities due to flow dynamic effects in the membrane (back pressure) rather than due to changes in the plasma conditions. Above all, the introduction of $\mathrm{N}_{2}$ as the make-up gas leads to new significant spectral interferences and is therefore not advisable. As an example, the ${ }^{40} \mathrm{Ar}^{15} \mathrm{~N}$ and ${ }^{40} \mathrm{Ar}^{14} \mathrm{~N}^{1} \mathrm{H}$ interferences on ${ }^{55} \mathrm{Mn}$ are increased by almost two orders of magnitude leading to a background equivalent concentration of about $5 \mathrm{ng} \mathrm{g}^{-1}$. Another example is shown in Fig. 3 for ${ }^{52} \mathrm{Cr}$. It is evident, that polyatomic species ${ }^{40} \mathrm{Ar}^{12} \mathrm{C}$ and ${ }^{36} \mathrm{Ar}^{16} \mathrm{O}$ are reduced significantly, whereas ${ }^{38} \mathrm{Ar}^{14} \mathrm{~N}$ appears to become significant besides an additionally appearing ${ }^{12} \mathrm{C}^{12} \mathrm{C}^{14} \mathrm{~N}^{14} \mathrm{~N}$ interference.

As already reported in previous studies ${ }^{26}$ samples with high viscosity and high total salt concentration lead to a blockage of the membrane and require thorough rinsing after every 10 samples. In comparison to the MCN100, the wider orifice of the central tubing of the MCN6000 nebuliser leads to less pronounced clogging of the nebuliser itself. The MCN100 shows significant problems, when introducing high viscose matrices such as the milk digest, since the matrix can lead to the clogging of the nebuliser. It is important to keep a continuous flow through the capillary, since small air bubbles lead to a stop

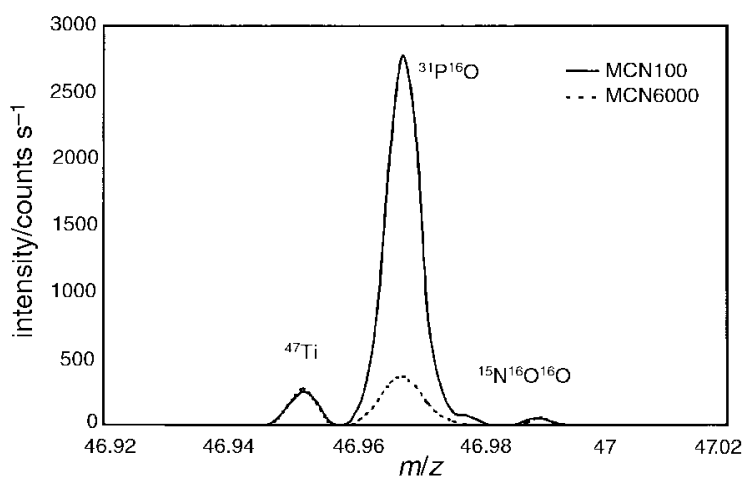

Fig. 2 Mass spectrum of ${ }^{47} \mathrm{Ti}$ at medium mass resolution $(m / \Delta m=4000)$ in a digested milk sample measured using the MCN100 and the MCN6000.

J. Anal. At. Spectrom., 2000, 15, 335-340 


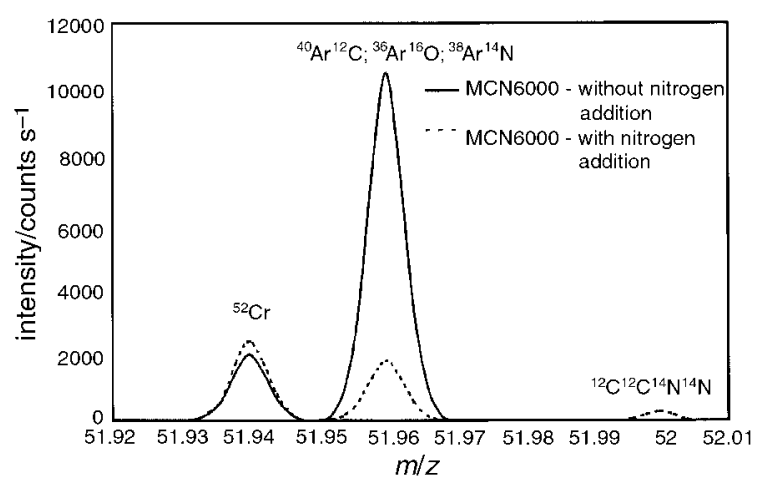

Fig. 3 Mass spectrum of ${ }^{52} \mathrm{Cr}$ at medium mass resolution $(\mathrm{m} /$ $\Delta m=4000$ ) of a digested milk matrix measured by MCN6000 with and without adding $\mathrm{N}_{2}$ as make-up gas.

of the flow caused by backpressure by the sample gas at the nebulising tip due to the high viscosity of the solution. If this occurs, the sample gas has to be shut off and, after switching on the sample gas again, a continuous flow can again be established. Operation in self-aspirating mode is therefore almost impossible for these solutions and a continuous flow has to be established by using a peristaltic pump. Moreover, the use of an internal standard is important in order to monitor clogging effects on the nebuliser.

\section{Non-spectral interferences-internal standardisation}

As is now well known, a nitric acid matrix causes significant suppression of the analyte signal because of the high concentration of easily ionisable elements as well as drifts caused by changing nebulisation efficiency with respect to viscosity and salt concentration, besides salt deposition on the sampler and skimmer cones. ${ }^{26,27}$ Signal intensities of analyte elements and possible internal standard elements were monitored with respect to nitric acid concentration. The same set of investigations were performed using a spiked and digested milk matrix and it was observed that the matrix suppression is mainly caused by the nitric acid matrix and the additional influence of the digested milk matrix is negligible. Fig. 4 shows the relative signal intensity of the four investigated candidate internal standards ${ }^{102} \mathrm{Ru},{ }^{103} \mathrm{Rh},{ }^{115} \mathrm{In}$ and ${ }^{187} \mathrm{Re}$ as a function of the $\mathrm{HNO}_{3}$ concentration. As can be readily observed for all four isotopes, strong signal suppression caused by higher $\mathrm{HNO}_{3}$ concentration was found as an overall trend and is not necessarily linear, especially in a $\mathrm{HNO}_{3}$ concentration range of $<10 \%$. However, the extent of signal suppression varies considerably with the investigated element. Therefore, the trends observed were systematically evaluated for the investigated trace elements with respect to the possible internal standard solutions of ${ }^{102} \mathrm{Ru},{ }^{103} \mathrm{Rh},{ }^{115} \mathrm{In}$ and ${ }^{187} \mathrm{Re}$. ${ }^{102} \mathrm{Ru},{ }^{103} \mathrm{Rh}$, and ${ }^{187} \mathrm{Re}$ show comparable trends. Finally, Rh

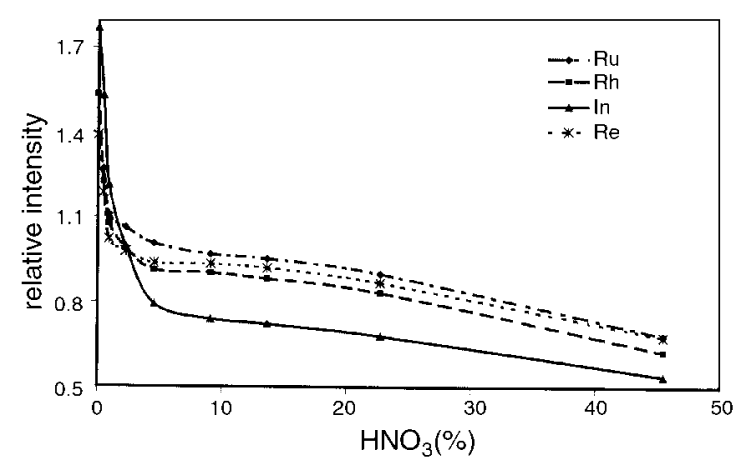

Fig. 4 Relative signal intensity (signal intensity normalised to the intensity as found in water) of ${ }^{102} \mathrm{Ru},{ }^{103} \mathrm{Rh},{ }^{115} \mathrm{In}$ and ${ }^{187} \mathrm{Re}$ as function of $\mathrm{HNO}_{3}$ concentration. was selected to be the best matching internal standard for the elements $\mathrm{V}, \mathrm{Cr}$, Co and $\mathrm{Ni}$. Indium was selected to be most suitable for the quantification of $\mathrm{Al}, \mathrm{Mn}, \mathrm{Cu}$ and $\mathrm{Pb}$ whereas $\mathrm{Re}$ was selected for $\mathrm{Sc}, \mathrm{Ag}, \mathrm{Pt}$ and $\mathrm{Au}$. Ti, Fe, As and $\mathrm{Cd}$ did not show a significantly matching curve compared to the internal standards. With an absolute difference of less than $5 \%$, In was selected as internal standard for Ti and Fe. For As and $\mathrm{Cd}$, additional correction factors were used to correct for different matrix suppression. This procedure is relevant, since the matrix of the milk digest is constant (about $8 \% \mathrm{HNO}_{3}$ ) and, as is evident from Fig. 4, this concentration is already in a range, where slight changes in the matrix composition do not lead to a significant change in matrix suppression. Therefore, a simple multiplicative factor can be applied. Recovery rates on spiked milk digests were $100+3 \%$. Table 3 gives an overview of the investigated elements and the best matching internal standards and selected resolution settings.

\section{Analysis of the milk samples}

Detection limits as reported in Table 4 are procedural detection limits, i.e., including the whole sample preparation procedure and used chemicals, and are 3 times the standard deviation of an average of $n=10$ individually prepared blank solutions (i.e., 10 different blanks were prepared, digested and measured individually on 2 different days). Values are calculated for an equivalent concentration as found in $1.5 \mathrm{~g}$ milk or $0.30 \mathrm{~g}$ milk powder, respectively.

Elemental concentration was derived by the external calibration method as explained in detail in the experimental section. The RSD of the single analysis was better than 3\%. To test the accuracy and the precision of the analytical procedure (mineralisation, dilution, ICP-MS analysis by external calibration and internal standardisation), the aqueous calibration was checked by measuring the TM27 water standard. Moreover, a milk powder reference material (BCR 063 - natural) was analysed every five samples. Elemental concentrations and standard deviations of the milk powder reference material (BCR 063 - natural) are summarised in Table 5, which gives the mean and the standard deviation $(s)$ of $n=6$ individual measurements. The experimental concentrations are in good agreement with certified and information values or values reported in the literature. ${ }^{23}$

Table 6 shows the results of the investigated milk samples using the optimised instrumental set-up. Concentrations of the trace elements varied considerably from sample to sample. The observed variations of trace element concentrations in human milk can be ascribed to differences in intake related to environmental conditions. Hence, large differences in the concentrations of trace elements in milk among mothers are

Table 3 Selected isotopes, internal standards and resolution mode for the ICP-MS measurement of trace elements in human milk

\begin{tabular}{lll}
\hline Isotope & Internal standard & Resolution \\
\hline${ }^{27} \mathrm{Al}$ & $\mathrm{In}$ & 4000 \\
${ }^{45} \mathrm{Sc}$ & $\mathrm{Re}$ & 4000 \\
${ }^{47} \mathrm{Ti}$ & $\mathrm{In}$ & 4000 \\
${ }^{51} \mathrm{~V}$ & $\mathrm{Rh}$ & 4000 \\
${ }^{52} \mathrm{Cr}$ & $\mathrm{Rh}$ & 4000 \\
${ }^{55} \mathrm{Mn}$ & $\mathrm{In}$ & 4000 \\
${ }^{56} \mathrm{Fe}$ & $\mathrm{In}$ & 4000 \\
${ }^{59} \mathrm{Co}$ & $\mathrm{Rh}$ & 4000 \\
${ }^{60} \mathrm{Ni}$ & $\mathrm{Rh}$ & 4000 \\
${ }^{63} \mathrm{Cu}$ & $\mathrm{In}$ & 4000 \\
${ }^{75} \mathrm{As}$ & $\mathrm{In}$ & 8000 \\
${ }^{109} \mathrm{Ag}$ & $\mathrm{Re}$ & 400 \\
${ }^{114} \mathrm{Cd}$ & $\mathrm{In}$ & 400 \\
${ }^{195} \mathrm{Pt}$ & $\mathrm{Re}$ & 400 \\
${ }^{197} \mathrm{Au}$ & $\mathrm{Re}$ & 400 \\
${ }^{208} \mathrm{~Pb}$ & $\mathrm{In}$ & 400 \\
\hline
\end{tabular}


Table 4 Detection limits in $\mathrm{ng} \mathrm{g}^{-1}$ milk or ready to drink formulae (liquid) and $\mathrm{ng} \mathrm{g}^{-1}$ milk powder (solid)

\begin{tabular}{lcc}
\hline Element & LOD (milk)/ng g & LOD (milk powder) $/ \mathrm{ng} \mathrm{g}^{-1}$ \\
\hline $\mathrm{Al}$ & 10 & 50 \\
$\mathrm{Sc}$ & 0.13 & 0.67 \\
$\mathrm{Ti}$ & 2.7 & 13 \\
$\mathrm{~V}$ & 0.07 & 0.33 \\
$\mathrm{Cr}$ & 0.80 & 4.0 \\
$\mathrm{Mn}$ & 0.80 & 4.0 \\
$\mathrm{Fe}$ & 35 & 173 \\
$\mathrm{Co}$ & 0.07 & 0.33 \\
$\mathrm{Ni}$ & 0.13 & 0.67 \\
$\mathrm{Cu}$ & 1.3 & 6.7 \\
$\mathrm{As}$ & 1.3 & 6.6 \\
$\mathrm{Ag}$ & 0.13 & 0.67 \\
$\mathrm{Cd}$ & 0.07 & 0.33 \\
$\mathrm{Pt}$ & 0.01 & 0.03 \\
$\mathrm{Au}$ & 0.05 & 0.27 \\
$\mathrm{~Pb}$ & 0.27 & 1.3 \\
\hline
\end{tabular}

not unexpected, because nutritional habits, trace element deposition in the body, differences in resorption of trace elements from the food, the transport of trace elements and the mobilisation of trace elements influence the availability of trace elements to the milk producing glands. Increased concentrations of precious metals, i.e., $\mathrm{Au}$ and $\mathrm{Ag}$, are part of ongoing discussions and possible sources are jewellery or dental fillings. Moreover, living conditions (environmental pollution, food uptake, smoking ) of the mothers have to be monitored more comprehensively to draw further conclusions.

Since formulae are suspensions in tap water with 13 to $15 \%$ by mass of powders specially prepared from cow milk or soy beans, doses provided by such formulae may vary considerably and will depend on the natural concentrations of trace elements in the powder, the composition of the drinking water, and the degree of fortification. ${ }^{23}$ Table 6 shows the concentration ranges of the 17 investigated trace elements determined in four different formulae (prepared ready to drink).

Local Viennese tap water (from the Alps) which is used for the preparation of the formulae was investigated for its total elemental contribution to the 'ready to drink' formulae. The concentrations of $\mathrm{Ni}, \mathrm{Cu}, \mathrm{Ag}$ and $\mathrm{Pt}$ of the final milk solution were found to be significantly influenced by tap water used for preparing the formula, whereas the concentration of $\mathrm{Au}, \mathrm{Al}$, $\mathrm{Sc}, \mathrm{Ti}, \mathrm{Cr}, \mathrm{Mn}, \mathrm{Fe}$ and $\mathrm{Co}$ are predominantly influenced by the powder itself. Furthermore, a batch-to-batch variability in the concentrations of trace elements was observed, which may be the result of changes of these concentrations in the raw
Table 6 Observed concentration range of eight toxic (Ag, Al, As, Au, $\mathrm{Pt}, \mathrm{Sc}$ and $\mathrm{Ti}$ ) and seven essential (Co, $\mathrm{Cr}, \mathrm{Cu}, \mathrm{Fe}, \mathrm{Mn}, \mathrm{Ni}$ and $\mathrm{V})$ elements in human milk and infant formulae (prepared ready to drink)

\begin{tabular}{lll}
\hline Element & Human milk/ng g & Ready to drink infant formulae/ng g \\
\hline $\mathrm{Ag}$ & $<0.13-42$ & $<0.13-0.67$ \\
$\mathrm{Al}$ & $<10-380$ & $50-500$ \\
$\mathrm{As}$ & $<1.3-30$ & not determined \\
$\mathrm{Au}$ & $0.1-2.1$ & $<0.05-0.20$ \\
$\mathrm{Pt}$ & $<0.01-0.04$ & $<0.01$ \\
$\mathrm{Sc}$ & $<0.13-1.2$ & $<0.13$ \\
$\mathrm{Ti}$ & $<2.7-114$ & $<2.7-5.1$ \\
$\mathrm{Co}$ & $<0.07-1.5$ & $0.70-1.1$ \\
$\mathrm{Cr}$ & $<0.8-163$ & $<0.8-15$ \\
$\mathrm{Cu}$ & $90-1400$ & $920-2550$ \\
$\mathrm{Fe}$ & $110-1570$ & $1400-12500$ \\
$\mathrm{Mn}$ & $1.8-25$ & $29-55$ \\
$\mathrm{Ni}$ & $<0.13-6.4$ & $11-18$ \\
$\mathrm{~V}$ & $<0.07-3.7$ & $0.25-0.75$ \\
\hline
\end{tabular}

materials for the preparation of the powders and may also be caused by the production process. Therefore, the tap water and batch variabilities must be considered, when recommendations about daily intakes of trace elements with formulae are promulgated for infants.

\section{Conclusion}

The work described has shown that the high sensitivity, simple spectra and low detection limits of ICP-SFMS make this method an ideal analytical tool for the determination of trace elements in milk. Even elements ( $\mathrm{Sc}, \mathrm{Ti}, \mathrm{V}, \mathrm{Cr}, \mathrm{Mn}, \mathrm{Fe}, \mathrm{Ni}, \mathrm{Co}$ ), which were not easily accessible by ICP-QMS for investigations so far, could be analysed reliably since the problem of spectral interferences can be met by the enhanced mass resolution capability of ICP-SFMS. The matrix induced suppression can be compensated for by the use of an adequate internal standard, even if the use of internal standards is not straight forward. Thus, it is still important to investigate spectral and non spectral interferences properly with respect to the introduced matrix, since they significantly influence the accuracy of the results.

The use of a MCN6000 as the introduction system reduced the spectral interfering molecular ions, but did not eliminate them, to a negligible amount, whereas no improvement of the signal intensities could be reported in comparison to a conventional MCN100 (all in combination with a shielded torch). Hence, $\mathrm{Sc}, \mathrm{Al}, \mathrm{Ti}, \mathrm{V}, \mathrm{Cr}, \mathrm{Mn}, \mathrm{Fe}, \mathrm{Co}, \mathrm{Ni}$ or $\mathrm{Cu}$ still had

Table 5 ncentration of 16 trace elements in the skim milk powder reference material (BCR063)

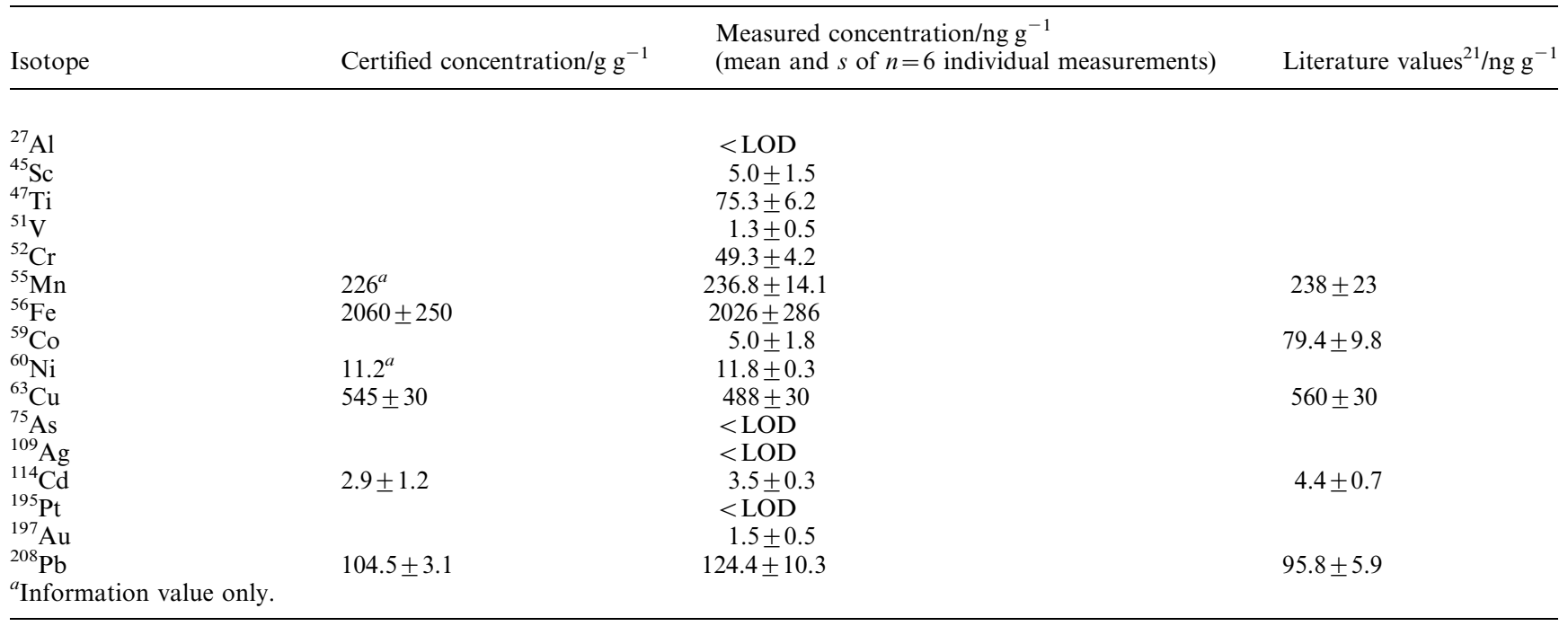


an interfered analytical signal in low mass resolution even when matrix desolvation was applied. Thus, the relatively complex nebulising unit does not lead to a significant improvement in the performance of the measurement of the digested milk matrix. In general, the use of a microconcentric nebuliser is not satisfactory, especially with respect to clogging effects. Other nebulising units, e.g., a low flow nebuliser in combination with a cyclone spray chamber, will provide the same results in terms of signal intensities with the advantage of a more robust introduction system, which can be operated even in self aspirating mode. This system still gives the advantage of low sample uptake rates, which are required, if only limited amounts of solution are available (uptake of $200 \mu \mathrm{L} \mathrm{min}^{-1}$ compared to $30 \mu \mathrm{L} \mathrm{min}{ }^{-1}$ for the MCN100 or $60 \mu \mathrm{L} \mathrm{min}^{-1}$ for the MCN6000). On the other hand, the increased water vapour load of the non-cooled cyclone spray chamber can be, in general, a source of increased oxygen-containing polyatomic interferences.

The observed concentration ranges in human milk samples agreed well all in all the ranges for those elements, which are reported so far. For some elements no values are currently available in the literature. A more comprehensive investigation on these elements is therefore necessary. Concentrations of trace elements in infant formulae and in human milk must be investigated in more detail, especially with respect to uptake rates of trace elements in the human body. Moreover, the significant variations in batches must be considered with respect to the production process of the milk powder.

\section{References}

1 B. L. Failla, U. Babu and K. E. Seidel, J. Nutr., 1988, 118, 487.

2 K. M. Hambidge, C. Hambidge, M. A. Jacobs and J. D. Baum, Paediatr. Res., 1972, 6, 868

3 K. Chandra, Paediatrics, 1980, 66, 781

4 M. Takada, M. Shimada, S. Hosono, M. Tauchi, M. Minato, S. Takanashi, M. Okuni and S. Takeuchi, Early Hum. Dev., 1992, 29, 333 .

5 W. Wertz, in Health evaluation of heavy metals in infant formula and junior food, ed. E. Schmidt and A. Hildebrand, Springer, Berlin, 1983, 47.
6 R. Chierici, C. Gamboni and V. Vigi, Acta Paediatr. Suppl., 1994, 402, 50.

7 J. Z. Li, J. Yoshinaga, T. Suzuki, M. Abe and M. Morita, J. Nutri. Sci. Vitaminol., 1990, 36, 65.

8 M. Krachler, F. Shi Li, E. Rossipal and K. J. Irgolic, J. Trace Elem. Med. Biol., 1998, 12, 159.

9 M. Krachler, E. Rossipal and D. Micetic-Turk, Eur. J. Clin. Nutr., 1999, 53, 1 .

10 B. Lönnerdal, in Iron nutrition in infancy and childhood, ed A. Stekel, Nestlé nutrition workshop series, Ravens press, New York, 1984, 4, 95

11 L. Perrone, L. Di Palma, R. Di Toro, G. Gialanella and R. Moro, Biol. Trace Elem. Res., 1994, 41, 321.

12 P. Schramel, G. Lill, S. Hasse and B. Klose, Biol. Trace Elem. Res., 1988, 16, 67.

13 N. Z. Nyazema, O. Mahomva and W. Andifasi, Afr. J. Med. Sci., 1989, 18, 159

14 Minor and trace elements in breast milk, Report of a joint WHO/ IAEA collaborative study, 1989, World Health Organization, Geneva.

15 F. S. Li, E. Rossipal and K. J. Irgolic, Thyroid, 1996, 6, 147.

16 C. E. Casey, M. C. Neville and K. M. Hambidge, Am. J. Clin Nutr., 1989, 49, 773.

17 C. E. Casey, P. A. Walravens and K. M. Hambidge, Pediatrics, 1981, 68, 394.

18 T. Alkanani, J. K. Friel and H. P. Longerich, J. Agric. Food Chem., 1994, 42, 1965.

19 D. Amarasiriwardena, M. Kotrebai, A. Krushevska and R. M. Barnes, Can. J. Anal. Sci. Spectrosc., 1997, 42, 69.

20 K. E. Jarvis, A. L. Gray and R. S. Houk, Handbook of Inductively coupled plasma mass spectrometry, Blackie, London, 1992.

21 N. Jakubowski, L. Moens and F. Vanhaecke, Spectrochim. Acta Part B, 1998, 53, 1739.

22 M. Krachler, E. Rossipal and K. Irgolic, Biol. Trace Elem. Res., 1998, 65, 53.

23 M. Krachler, A. Alimonti, F. Petrucci, K. J. Irgolic, F. Forastiere and S. Caroli, Anal. Chim. Acta, 1998, 363, 1.

24 L. Moens and N. Jakubowski, Anal. Chem., 1998, 70(1), 251A.

25 T. Prohaska, S. Hann, C. Latkoczy and G. Stingeder, J. Anal. At. Spectrom., 1999, 14, 1.

26 F. Vanhaecke, J. Riondato, L Moens and R. Dams, Fresenius J. Anal. Chem., 1996, 355, 397.

27 M. Krachler, H. Radner and K. J. Irgolic, Fresenius' J. Anal. Chem., 1996, 355, 120.

Paper a907026e 